\title{
A IMPORTÂNCIA DA PAISAGEM NA LEITURA DAS ESPACIALIDADES
}

\author{
The importance of landscape in reading specialties
}

La importanciadelpaisajeenlas especialidades de lectura

\author{
Lânderson Antória Barros* \\ Antonio Carlos Castrogiovanni** \\ Christiano Corrêa Teixeira***
}

* Doutorando Posgea UFRGRS - landerson-barros@hotmail.com

**Professor Doutor UFRGS - castroge@ig.com.br

***Doutorando Posgea UFRGRS - christiano.teixeira@ufrgs.br

Recebido em 08/10/2019. Aceito para publicação em 20/10/2019.

Versão online publicada em 10/11/2019 (http://seer.ufrgs.br/paraonde)

\section{Resumo:}

A pesquisa desenvolvida buscou, inicialmente, refletir e (re)textualizar os conceitos de Paisagem através do olhar de diferentes autores. Em um segundo momento procura responder provisoriamente às questões: a Paisagem é informação ou conhecimento? Como transformar a Paisagem em conhecimento espacial? O empírico visto é a Paisagem ou já é abstração? É uma pesquisa de caráter exploratório com reflexão coletiva que se aproxima de uma pesquisa-ação. A leitura é feita a partir dos princípios hologramático e dialógico da Complexidade. Avaliar as diferentes espacialidades inseridas em temporalidades são fundamentais para que os sujeitos professores possam transformar a Paisagem num refletir a geograficidade existente nos diferentes locais A percepção da Paisagem encaminha para a leitura de espacialidades que revelam os elementos que a compõem: localização, forma, arranjos espaciais, escalas e lugares, (re)construídos e interagidos, contidos em uma parte do espaço que representa o todo, onde a soma das partes é mais que o todo. Assim, parece ser fundamental considerar a dinâmica sócio espacial que envolve os aspectos visíveis e invisíveis, implícitos e explícitos, que falam ou silenciam, de acordo com as subjetividades geográficas do olhar dirigido pelos sujeitos às paisagens, procurando não separar sujeito do objeto percebido. Neste artigo apresentamos algumas das questões já respondidas por esta pesquisa.

Palavras-chave: Paisagem. Arranjo Espacial. Forma.Lugar.

\section{Abstract:}

The research developed initially sought to reflect and (re) textualize the concepts of landscape through the eyes of different authors. In a second moment it tries to answer provisionally the questions: Landscape is information or knowledge? How to turn landscape into spatial knowledge? Is the empirical seen Landscape or is it already abstraction? It is an exploratory research with collective reflection that approaches an action research. The reading is made from the holographic and dialogical principles of Complexity. Evaluating the different spatialities inserted in temporalities are fundamental for the teachers subject to transform the landscape into reflect the existing geography in different places. The perception of the landscape leads to the reading of spatialities that reveal the elements that compose it: location, shape, spatial arrangements. , scales and places, (re) constructed and interacted, contained in a part of space that represents the whole, where the sum of the parts is more than the whole. Thus, it seems to be fundamental to consider the socio-spatial dynamics that involve the visible and invisible, implicit and explicit aspects that speak or silence, according to the geographical subjectivities of the gaze directed by the subjects to the landscapes, trying not to separate subject from the perceived object. In this article we present some of the questions already answered by this research. 
Key-words:Landscape. Space Arrangement. Form. Place.

\section{Resumen:}

La investigación desarrollada inicialmente buscó reflejar y (re) textualizar los conceptos de paisaje a través de los ojos de diferentes autores. En un segundo momento trata de responder provisionalmente las preguntas: ¿El paisaje es información o conocimiento? ¿Cómo convertir el paisaje en conocimiento espacial? ¿Es el paisaje empírico visto o ya es abstracción? Es una investigación exploratoria con reflexión colectiva que se acerca a una investigación en acción. La lectura se realiza a partir de los principios holográficos y dialógicos de la Complejidad. Evaluar las diferentes espacialidades insertadas en las temporalidades es fundamental para que los profesores sujetos transformen el paisaje para reflejar la geografía existente en diferentes lugares. La percepción del paisaje lleva a la lectura de espacialidades que revelan los elementos que lo componen: ubicación, forma, arreglos espaciales. , escalas y lugares, (re) construidos e interactuados, contenidos en una parte del espacio que representa el todo, donde la suma de las partes es más que el todo. Por lo tanto, parece ser fundamental considerar la dinámica socioespacial que involucra los aspectos visibles e invisibles, implícitos y explícitos que hablan o silencian, de acuerdo con las subjetividades geográficas de la mirada dirigida por los sujetos a los paisajes, tratando de no separar al sujeto del objeto percibido. En este artículo presentamos algunas de las preguntas ya respondidas por esta investigación.

Palabras-clave:Paisaje. Arreglo espacial. Forma.

\section{Introdução - Trajeto inicial}

A Paisagem é um conceito polissêmico, que possui uma vasta gama de possibilidades, contudo percebemos muitas vezes que limitamos o nosso olhar apenas ao belo, no entanto, enquanto educadores a nossa abordagem deve ir além, ser mais ampla. Não podemos nos limitar a primeira informação percebida. A Paisagem tem um silêncio que precisa ser escutado.

A fim de aproximar o conceito de Paisagem com o ensino de Geografia, inicialmente, vamos trazer algumas provocações tencionando a possiblidade de transformarmos a Paisagem em conhecimento espacial. Essas reflexões serão realizadas ao longo do texto através de uma pesquisa, inicialmente, baseada na revisão bibliográfica buscando refletir e (re)textualizar os conceitos de Paisagem através do olhar de diferentes autores (colocar os autores).

A pesquisa possui caráter exploratório com reflexão coletiva que se aproxima de uma pesquisa-ação. As respostas são buscadas provisoriamente nas experiências de sala de aula que cada integrante do grupo realiza. A leitura metodológica é feita a partir dos princípios hologramático e dialógico da Complexidade que nos possibilitam a observar ser, "a condição humana marcada por duas grandes incertezas: a incerteza cognitiva e a incerteza histórica. [...] Conhecer e pensar não é chegar a uma verdade absolutamente certa, mas dialogar com a incerteza. (MORIN, 2000, p.59)". O pensamento complexo trata com a incerteza, procurando conceber a organização provisória do pensamento, portanto nos provoca ler o mundo por diferentes caminhos.

O princípio hologramático é inspirado na ideia do holograma, na qual cada

ParaOnde!?, Porto Alegre, v.12 n.2, p.39-48, 2019.http://seer.ufrgs.br/paraonde Edição Especial - III Colóquio de Pesquisadores em Geografia Física Ensino de Geografia 
ponto, paisagem, contém a quase totalidade da informação do espaço representado. Coloca em evidência o aparente paradoxo nos sistemas complexos, em que o todo está nas diferentes partes, como as partes estão no todo. Se tomarmos o Espaço Geográfico, o todo espacial está nas diferentes paisagens e as diferentes paisagens fazem parte do todo, pois as relações que se estabelecem não respeitam, necessariamente, os limites políticos/territoriais/culturais do espaço. A questão é descobrir este todo na parte!

Já o princípio dialógico pode ser entendido "como sendo uma associação complexa (complementar/concorrente/antagônica) de instâncias necessárias em conjunto à existência, ao funcionamento e ao desenvolvimento de um fenômeno organizado (MORIN, 1999a, p. 110)". A dialógica permite assumir, racionalmente, a associação de ações contraditórias, para conceber um imenso fenômeno complexo - neste caso, a paisagem.

\section{Construção teórica - Caminhando}

O conceito de Paisagem não é de uso exclusivo da Geografia, porém sempre teve grande importância para a ciência. A "paisagem" se constitui como um conceito chave para a Geografia, conforme apontam Corrêa e Rosendhal (1998, p.7).

A Geografia busca possibilitar a compreensão do mundo que vivemos, ancorada em uma abordagem pautada nas ações humanas das mais variadas sociedades existentes no planeta. Ela corrobora para a criação de uma identidade única que se manifesta de diferentes formas. A Paisagem é percebida na Geografia por meio de inúmeras dimensões, possibilitando uma certa polissemia, de acordo com foco epistemológico da abordagem utilizada, a partir do olhar dos pesquisadores e leitores. Do ponto de vista clássico, a Geografia lê a Paisagem como algo materializado no espaço, sendo geralmente relacionada ao alcance visual.

Diante desses aspectos, optamos por compreender a Paisagem a partir de diferentes aspectos buscando a multiplicidade existente nesse conceito a fim de encontrarmos a totalidade de elementos. Porém, cabe destacar que nessa busca não podemos cair em uma mera junção de elementos geográficos. Conforme nos aponta Bertrand:

A paisagem não é a simples adição de elementos geográficos disparatados. É, em uma determinada porção do espaço, o resultado da combinação dinâmica, portanto instável, de elementos físicos, biológicos e antrópicos que, reagindo dialeticamente uns sobre os outros, fazem da paisagem um conjunto único e indissociável, em perpétua evolução. A dialética tipo-indivíduo é próprio fundamento do método de pesquisa. (BERTRAND,2004, p.141)

Milton Santos compreende que a Paisagem não é um mero sinônimo do conceito de espaço, sendo ela uma materialização do Espaço Geográfico através da forma. Para Santos (1997, p. 83) Paisagem é o conjunto de formas que, num dado momento, exprimem as heranças que representam as sucessivas relações localizadas entre a sociedade e a natureza. Ou ainda, a Paisagem se dá como

ParaOnde!?, Porto Alegre, v.12 n.2, p.39-48, 2019.http://seer.ufrgs.br/paraonde Edição Especial - III Colóquio de Pesquisadores em Geografia Física Ensino de Geografia 
conjunto de objetos reais concretos e imaginários.

Nessa perspectiva, podemos perceber que Santos entende a Paisagem para além do tempo, possibilitando a união de objetos do passado e presente, compreendo a Paisagem como um sistema material.

Quando falamos sobre Paisagem, quais são, provavelmente, as imagens que surgem no pensamento? Distante de definições conceituais, as respostas geralmente apontam para locais cujos atributos perceptíveis relacionados à beleza estética possuem destaque: uma praia de águas límpidas, montanhas verdejantes, cenas de um ambiente urbano. Essa parece ser a dimensão cotidianamente atribuída à Paisagem. Talvez um tanto idealizada da mesma. Ao comentar sobre esses aspectos, não queremos asseverar que a Paisagem não possa ser isto. Pelo contrário, desejamos demonstrar que a Paisagem possui essa e outras múltiplas interpretações e significados.

Segundo Barthes (1990, p. 32), "[...] toda a Imagem é polissêmica e pressupõe, subjacente a seus significantes, uma 'cadeia flutuante' de significados, podendo o leitor escolher alguns e ignorar outros". As espacialidades que traduzem o Espaço Geográfico parecem ser, antes de tudo, imagens. Surgem, então, duas questões: como são/podem ser construídos/escolhidos estes significados? Eis outra de nossas interrogações que são inquietudes que temos, e que esta pesquisa em outros momentos procurará responder.

A Paisagem opera como um dos principais demonstrativos da forma como os sujeitos, em sua relação com a natureza, se apropriam do espaço modificando-o e adequando-o conforme as suas intenções, necessidades, crenças, enfim, a sua cultura. Essa concepção vai ao encontro das formulações de Verdum (2012).

A Paisagem demonstra as formas observadas e interpretadas de acordo com o sujeito que a experiência. Mas ela, por si só, não é autoexplicativa. Aqui está uma importante contribuição do professor que deve propor o seu trabalho com a noção de que a Paisagem vai além do olhar. Uma das múltiplas potencialidades deste conceito está na possibilidade de interação com os demais sentidos. As paisagens contêm formas e cores, mas dentro destes elementos também estão presentes sons, cheiros e sabores que podem enriquecer e aprofundar nossas perspectivas propiciando a análise da Paisagem enquanto resultado da manifestação aparente das espacialidades.

Longe de dicotomizarmos a Paisagem entre a rigidez de categorias como Paisagem Natural e Humanizada, pensamos que toda Paisagem tenha um caráter fundamentalmente cultural visto que ela enquanto conceito para análise da realidade é um constructo social inserido numa cultura ou culturas. Mas será a Paisagem um conhecimento ou uma informação? Pensamos que, inicialmente, seja necessário diferenciarmos informação e conhecimento.

As informações são unidades dispersas e designáveis sob a forma de bits. Ou seja, informações espalhadas, separadas e distantes. Já o conhecimento diz respeito às informações operadas de maneira organizada, supondo uma relação de abertura e de fechamento entre o conhecendo e o conhecido. A Paisagem, nesta perspectiva, apresenta-se de maneira objetiva como um conjunto de informações, cabendo ao observador a organização das informações contidas na mesma para

ParaOnde!?, Porto Alegre, v.12 n.2, p.39-48, 2019.http://seer.ufrgs.br/paraonde Edição Especial - III Colóquio de Pesquisadores em Geografia Física Ensino de Geografia 
permitir o seu entendimento.

A Paisagem parece ser uma díade entre o objetivo e o subjetivo. Ela é objetiva, pois demonstra a forma, a parte concreta e materializada. Mas também é agregadora de aspectos subjetivos, que envolvem a percepção por meio dos sentidos e os condicionamentos culturais as quais os sujeitos observadores da Paisagem estão submetidos. Ela é dialógica, à medida que expressa as dinâmicas sociais e culturais em que está inserida, mas também influencia e condiciona os sujeitos que a (trans)formam e a (re)constroem. Ao preconizar a Paisagem como um objeto de estudo também deve ser levado em conta a escala a ser explorada.

Carl Sauer (1889-1975) concebe a singularidade da Paisagem nas ações que nela ocorrem. Para ele, a Paisagem natural é o resultado do tempo na geologia, e a Paisagem cultural a atuação do homem naquela por meio de sua cultura. Nesta concepção cultural de Sauer, a morfologia da Paisagem parece se dar pela ação humana por meio de sua cultura, que nada mais é do que o modo como um grupo humano se apropria do espaço (neste caso o meio físico) e o transforma para atender às suas necessidades. No entanto, o autor ainda apresenta a distinção entre homem-natureza, mas depositando na cultura o papel de principal agente modificador do ecúmeno. Na esteira do pensamento de Sauer, a Geografia Cultural com Berqueaprofunda a concepção de que a Paisagem é produto de uma cultura, para tanto, o autor afirma que a Paisagem é marca e matriz. É marca na medida em que expressa uma civilização, e é matriz, pois contribui na concepção e representação (cultura) do espaço. Para tanto, argumenta que:

É preciso compreender a paisagem de dois modos: por um lado ela é vista por um olhar, apreendida por uma consciência, valorizada por uma experiência, julgada (e eventualmente reproduzida) por uma estética e uma moral, gerada por uma política, etc. E por outro lado, ela é matriz, ou seja, determina em contrapartida, esse olhar, essa consciência, essa experiência.(BERQUE, 1998, p. 86).

A ideia que Berque traz sobre Paisagem remete-nos à recursividade de Morin (2005). Ao considerar a Paisagem como produto (marca) da ação de uma cultura e como produtor (matriz), observamos uma autoprodução da Paisagem no pensamento do autor. Essas inter-relações exprimem a complexidade que está presente na constituição da Paisagem e o caráter simbólico que carrega.

Os autores Sauer (1998), Berque (1998) e Cosgrove (1998) são representantes de uma vertente humanista da Geografia, denominada de Geografia Cultural, que atribui à cultura de um grupo a força transformadora e criadora da paisagem. Contudo, somente a cultura é, em nosso ponto de vista, insuficiente para explicar um conceito tão complexo e impreciso. Apresentamos estas concepções a fim de incorporá-las à atuação de uma cultura na produção de uma paisagem, pois pensamos ser este um dos elementos que podem auxiliar na leitura da paisagem.

Além dos geógrafos de inclinação cultural, outras correntes da Geografia também contribuem para a compreensão da Paisagem a partir de sua perspectiva. A fenomenologia na Geografia tem em Eric Dardel um de seus autores mais singulares. Dotado de uma escrita particular e até mesmo poética, Dardel (2011) analisa a Paisagem de uma perspectiva intimista, particular, do indivíduo. Para ele, a

ParaOnde!?, Porto Alegre, v.12 n.2, p.39-48, 2019.http://seer.ufrgs.br/paraonde Edição Especial - III Colóquio de Pesquisadores em Geografia Física Ensino de Geografia 
Geografia pode ser a maneira pela qual o homem, individualmente ou coletivamente, exprime seu Ser no mundo, a maneira de se encontrar. É através de como constrói e transforma a Paisagem que o sujeito fala de si.

Segundo Dardel (2011), a Paisagem não é meramente contemplativa ou uma justaposição de elementos, constitui uma fala de homem para homem. Dos homens do passado para os homens do presente. Traduz espacialmente os conflitos de sua época, é a manifestação do homem no mundo, "a paisagem pressupõe uma presença do homem, mesmo lá onde toma a forma de ausência. Ela fala de um mundo onde o homem realiza sua existência como presença circunspecta e atarefada." (DARDEL, 2011, p.32). Então, a contribuição que Dardel nos dá, vai além do ser humano como social e coletivo, é a expressão do homem com a sua morada, o seu planeta em diferentes tempos.

Diferenciando-se do que até o momento tratamos sobre paisagem, Santos (1988) define Paisagem como:

[...] tudo aquilo que nós vemos, o que nossa visão alcança, é a paisagem. Esta pode ser definida como o domínio do visível, aquilo que a vista abarca. Não é formada apenas de volumes, mas também de cores, movimentos, odores, sons etc.(SANTOS, 1988, p.21).

Já Verdum (2012), apresenta uma ideia que se aproxima mais da dialogicidade, pois ao fundir elementos materiais da Paisagem com a subjetividade individual e coletiva, consegue transitar do concreto ao abstrato com propriedade. Pontua que:

[...] a paisagem é o concreto, ou seja, a coisa real, mas, ao mesmo tempo, é a imaginação, a representação destas coisas, as imagens. Cada um de nós, de acordo com nossa trajetória, nossa consciência, experiência, vê as paisagens de forma diferente e única. Cada um constrói seus conceitos que vão refletir em suas ações e olhares, mas estes olhares estão concebidos a partir de uma matriz cultural, do coletivo das pessoas de uma determinada sociedade humana (VERDUM, 2012, p.18).

Ainda segundo o autor, a Paisagem "é o resultado da vida das pessoas, dos processos produtivos e da transformação da natureza. Neste sentido, a paisagem mostra a história da comunidade de um determinado lugar" (VERDUM, 2012, p. 21) - espacialidades e temporalidades. Na comunicação do/no Espaço Geográfico, por suscitar uma fascinação, as paisagens se traduzem por imagens. As imagens são abstrações das espacialidades, razão pela qual a Geografia se faz presente. As imagens têm tido uma valorização que supera, muitas vezes, a escrita. Isto ocorre, embora, na ordem da percepção, ela não solicite o mesmo tipo de consciência.

Barthes (1990) acredita que a palavra imagem está ligada à raiz de imitari, isso segundo uma antiga etimologia. A imagem é vista, de modo geral, como um centro de resistência ao sentido, como uma representação. Ela nos evidencia a existência das paisagens.

A princípio, toda imagem é/pode ser vista como uma similaridade da aparência, ou seja, das diferenciações nas quais o espaço se apresenta. Isto pode ser compreendido se desconsiderarmos tudo aquilo que (pode) está além ou aquém

ParaOnde!?, Porto Alegre, v.12 n.2, p.39-48, 2019.http://seer.ufrgs.br/paraonde Edição Especial - III Colóquio de Pesquisadores em Geografia Física Ensino de Geografia 
do modo como algo se apresenta aos nossos sentidos. Barthes (1990, p. 38-39), através da Semiologia, afirma que a imagem, em sua conotação, seria assim

... constituída por uma arquitetura de signos provindos de uma profundidade variada de léxicos (de idioletos), cada léxico, por mais profundo que seja, sendo codificado, [...]. A língua de Imagem não é apenas o conjunto de palavras emitidas [...], é também o conjunto de palavras recebidas: a língua deve incluir as surpresas do sentido. (BARTHES, 1990, p. 38-39)

Portanto, considerando o ângulo da significação, a imagem é polissêmica e pressupõe, subjacente a seus significantes, uma cadeia flutuante de significados. $O$ sujeito pode escolher alguns e desprezar outros. Entendemos que, em qualquer sociedade, há códigos culturais, que viabilizam a leitura, a apropriação, a construção de significados, referentes aos lugares que se constituem, a princípio, pelas possibilidades que as paisagens nos oferecem. Assim a imagem é, de uma certa maneira, o limite do sentido que os sujeitos constroem, como o sentido chega à imagem e onde termina o sentido, são questões que merecem nossas reflexões constantes. As imagens suscitam uma fascinação pelas paisagens, uma possibilidade de apropriação das espacialidades; já a palavra, uma apropriação. A imagem é plena, pode se tornar um sistema saturado; a palavra é fragmentária, é um sistema disponível. Reunidas, a segunda serve para desapontar a primeira, pois:

[...] a Imagem é certamente mais imperativa do que a escrita, impõe a significação de uma só vez, sem analisá-la, sem dispersá-la. [...]. A Imagem transforma-se numa escrita, a partir do momento em que é significativa: como a escrita, ela exige uma léxis. (BARTHES, 1980, p. 132).

No caso do Espaço Geográfico, as imagens que retratam as paisagens parecem embriagar, pois elas despertam emoções, sentimentos, fascinação; a palavra serve para balizar as emoções, os sentimentos e o fascínio. Ela é um sistema disponível, para limitar as imagens que nos possibilitem sentir as paisagens. Segundo, ainda, Barthes (1990), o mundo do sentido está dividido internamente entre o sistema, como cultura, e o sintagma, como natureza. Todas as obras de comunicação reúnem, por meio de dialéticas diversas e diversamente performantes, a fascinação de uma natureza - da narrativa, da diagene, do sintagma - e a inteligibilidade de uma cultura. Esta cultura é refugiada em alguns símbolos descontínuos, que os sujeitos declinam sob a proteção da palavra viva. Este processo advém do caldo cultural de cada sociedade e provoca uma operatoriedade entre as imagens literais, que são denotadas, reveladas por meio direto de sinais, e as conotadas, que são resultados da associação entre ideias e símbolos relacionados à cultura. Portanto, a imagem conotada é uma Imagem simbólica que densifica ainda mais a possibilidade de atribuirmos sentido às paisagens.

Podemos interpretar a Paisagem como "um dinâmico código de símbolos que nos fala da cultura de seu passado, de seu presente e também de seu futuro (NOGUÉ, 2008, p.11)", em outras palavras, o grau de decodificação/leitura dos símbolos que compõem a Paisagem podem ser mais ou menos complexos, mas serão eles que possibilitaram entendermos a temporalidade existente nelas e a projeção que podem nos oferecer sobre o futuro da organização do Espaço

ParaOnde!?, Porto Alegre, v.12 n.2, p.39-48, 2019.http://seer.ufrgs.br/paraonde Edição Especial - III Colóquio de Pesquisadores em Geografia Física Ensino de Geografia 


\section{Geográfico.}

Nós percebemos o mundo através dos nossos sentidos, os quais são limitados pelos elementos culturais e sociais. A imagem é a comunicação não-verbal das formas que constituem as paisagens. A questão é: qual imagem é atrativa e qual imagem é repulsiva. Uma questão que nos desperta é: como lidar com a comunicação, para dar sentido às paisagens que retratam as espacialidades e que são produzidas a partir das formas, que constituem o Espaço Geográfico? E, neste sentido, como construir uma imagem que cause possibilidade de fazer existir as paisagens sem desconsiderar as suas singularidades?

A Paisagem é uma síntese, uma abstração das imagens vistas/sentidas do que nossos sentidos numa temporalidade podem atribuir sentido. É preciso educar os sujeitos para exercerem uma autoria na leitura e interpretação das imagens que são possibilidades aparentes da Paisagem se fazerem existir. Esse processo de compreensão é marcado por pontos de interrogação e interlocução, visto que o conhecimento geográfico rompe com nossa zona de conforto problematizando e desestabilizando as verdades postas.

O desequilíbrio que o ensino geográfico permite é de extrema importância, contudo alcançá-lo não é uma tarefa fácil, pois estamos diante de um momento em que a complexidade da leitura e releitura da Paisagem exige um aprofundamento e comprometimento com o ensino. Callai (2004, p.5) aponta que fazer a leitura da Paisagem é, portanto, uma possibilidade para que seja lida a realidade, percebendo a história, o movimento, a mobilidade territorial, a seletividade espacial que é resultado do social. Mas a Complexidade nos aponta que a realidade é complexa, insegura e repleta de dúvidas. O professor deve considerar estas incertezas. Nessa busca constante de propor novas leituras, ressignificações o conceito de Paisagem se apresenta como uma importante ferramenta para a interpretação de fatos e fenômenos que, por vezes, passam desapercebidos no dia a dia, auxiliando assim a decodificação dessas espacialidades. Um dos conceitos que, cada vez mais, entendemos como fundamental nessa análise é o de escala. A Paisagem colocada em análise multiescalar revela distintas realidades e submete nossas observações a releituras. Entende-se que, do ponto de vista metodológico e didático, a Paisagem é um elemento que nos permite analisar as relações socioespaciais - integrando e propondo compreender a simultaneidade dos eventos geográficos.

\section{Considerações provisórias - É preciso continuar a caminhar!}

Este ensaio trouxe como principal objetivo apresentar o conceito de Paisagem como um importante articulador na educação geográfica. Importante evidenciar que o ensaio não tem a pretensão de propor um enfoque único e exclusivo. Logo, a multiplicidade escalar presente no conceito de Paisagem apresenta-se como uma luneta essencial para compreendermos as espacialidades existentes no local.

Os aspectos a serem pontuados e analisados devem ser pensados a partir das possibilidades que as experiências vividas pelos alunos possibilitem um diálogo que aproxime essas leituras à compreensão provisória da vida. Ao problematizarmos a leitura da Paisagem pontuando esses aspectos, incumbimos nossos alunos a agir

ParaOnde!?, Porto Alegre, v.12 n.2, p.39-48, 2019.http://seer.ufrgs.br/paraonde Edição Especial - III Colóquio de Pesquisadores em Geografia Física Ensino de Geografia 
com autonomia, ou seja, possibilitamos um empoderamento do seu agir sobre o espaço, possibilitando a sua tomada de consciência sobre o seu papel de atuação na construção de novas espacialidades, provocando-o a duvidar do olhar, do descrito, da imagem que muitas vezes se diz destituída de poder representativo.

\section{Referências}

BARTHES, Roland. Mitologias. 4. ed. São Paulo: DIFEL, 1980.

BARTHES, Roland. O Óbvio e o obtuso. Rio de Janeiro: Nova Fronteira, 1990.

BARTHES, Roland. O Prazer do texto. 5. ed. São Paulo: Perspectiva, 1999.

BERTRAND, G. Paisagem e geografia física global. R. RA'E GA, Curitiba, n. 8, p. 141-152, 2004. Editora UFPR.

BERQUE, Augustin. Paisagem-Marca, Paisagem-Matriz: elementos da problemática para uma Geografia Cultural. In: CORREAA, Roberto Lobato; ROSENDAHL, Zeny (Org.). Paisagem, Tempo e Cultura. Rio de Janeiro: Eduerj, 1998. p. 84-91. Tradução: Ednês Vasconcelos e Anne-Marie Milon Oliveira.

CALLAI, Helena Copetti $O$ estudo do lugar como possibilidade de construção da identidade e pertencimento. VIII CONGRESSO LUSO-AFRO-BRASILEIRO DE CIÊNCIAS SOCIAIS COIMBRA 16, 17 E 18 DE SETEMBRO DE 2004, Coimbra Portugal, 2004. Disponível em http://www.ces.uc.pt/lab2004/pdfs/HelenaCallai.pdf. Acesso em 18 de agosto de 2018.

COSGROVE, Denis. A Geografia está em toda parte: Cultura, simbolismo nas paisagens humanas. IN: CORRÊA, R. L.; ROSENDHAL, Z. Espaço e Cultura. Rio de Janeiro: EdUerj/Nepec, 1995.

COSGROVE, Denis. A Geografia está em toda parte: Cultura e simbolismo nas paisagens humanas. In: CORRÊA, Roberto Lobato; ROSENDAHL, Zeny (Org.). Paisagem, Tempo e Cultura. Rio de Janeiro: Eduerj, 1998. p. 92-122. Tradução: Olivia Lima da Silva.

CORRÊA, R. L.; ROSENDHAL, Z. Espaço e Cultura. Rio de Janeiro: EdUerj/Nepec,1995.

DARDEL, Eric. O Homem e a Terra: natureza da realidade geográfica. São Paulo: Perspectiva, 2011. $159 \mathrm{p}$.

MORIN, Edgar. O Método III - o conhecimento do conhecimento. Porto Alegre: Sulina, 1999.

MORIN, Edgar. A cabeça bem-feita: repensar a reforma, reformar o pensamento.

ParaOnde!?, Porto Alegre, v.12 n.2, p.39-48, 2019.http://seer.ufrgs.br/paraonde Edição Especial - III Colóquio de Pesquisadores em Geografia Física Ensino de Geografia 
Rio de Janeiro: Bertrand Brasil, 2000.

NOGUÉ, Joan. El Paisaje em la Cultura Contemporánea. Madrid: Biblioteca Nueva, 2008.

SANTOS, Milton. A Natureza do Espaço: Técnica e Tempo, Razão e Emoção. 4. ed. São Paulo: Editora da Universidade de São Paulo, 2006. 258 p.

SAUER, Carl. A Morfologia da Paisagem. In: CORRÊA, Roberto Lobato; ROSENDAHL, Zeny (Org.). Paisagem, Tempo e Cultura. Rio de Janeiro: Eduerj, 1998. p. 12-74. Tradução: Gabrielle Corrêa Braga.

SCHAFER, Murray. A afinação do mundo: Uma exploração pioneira pela história passada pelo atual do mais negligenciado aspecto do nosso ambiente: a paisagem sonora. São Paulo: Editora Unesp, 2001. 381 p. Tradução: Maria T. Fonterrada.

VERDUM, Roberto. Perceber e conceber paisagem. In: VERDUM, Roberto et al (Org.). Paisagem: leituras, significados e transformações. Porto Alegre: Editora da Ufrgs, 2012. p. 15-22. 